Working Paper 03/2010

10 May 2010

\title{
ANALYSING INTERCONNECTIVITY AMONG ECONOMIES
}

\author{
Alfred Wong and Tom Fong ${ }^{1}$ \\ Research Department \\ Hong Kong Monetary Authority
}

As international financial integration gathers pace, interconnectivity has increased tremendously among financial institutions, financial markets and financial systems, a phenomenon to which the recent global financial crisis perhaps provided the best testimony. The interconnectivity among financial entities at various levels is multilateral in dimension and highly complicated with numerous feedback loops. To contribute to the understanding of the complexity of the global financial system, this study shows how the interconnected relationships can be disentangled into simple and quantifiable bilateral interdependence linkages, using 11 Asia-Pacific economies as an example. A major finding is that all these economies register a significantly higher sovereign risk once the condition that another economy is in distress is imposed.

JEL Classification Numbers: F34, G13, G15

Keywords: Sovereign risk, Credit Risk, Value-at-Risk, Systemic Risk, Contagion, Spillover, Tail Risk, Asia Pacific, Quantile Regression

Authors’ E-Mail Addresses: alfred_yt_wong@ @hkma.gov.hk; tom_pw_fong@hkma.gov.hk

The views and analysis expressed in this paper are those of the authors, and do not necessarily represent the views of the Hong Kong Monetary Authority.

1 We would like to thank Hans Genberg and Cho-hoi Hui for their invaluable comments, and Lillie Lam and Leslie Shen for their excellent research assistance. Any remaining errors are ours. 


\section{Executive Summary:}

- As the global economy is closely interconnected, what appeared to be a domestic banking problem in the US turned into a full-blown global crisis in 2008. This suggests that in order to avoid underestimating the risk of an economy, one must take into account the interconnected nature of the global financial system.

- $\quad$ This study investigates the interconnectivity of the global financial system, using 11 Asia-Pacific economies as an example. The interconnectivity is focused on the relationships among the sovereign credit risks of these economies under extreme market circumstances. In the study we demonstrate how the highly complex multilateral interconnected relationships can be disentangled into simple bilateral interdependence linkages. This is done by estimating the change in the value-at-risk (VaR) of an economic or financial variable of the economy conditional upon some adverse circumstances of another economy.

- An important finding is that the VaR of the credit default swap (CDS) spreads of an economy in Asia Pacific at its 99th percentile rises by, on average, nine basis points or $45 \%$ if another economy in the region comes under the same level of stress. Hence, usual risk measures tend to significantly underestimate the true risk of the economy during extreme market conditions.

- In a bid to find out whether favourable circumstances would have an opposite impact of similar magnitude, we also estimate the change in the VaR of the CDS spread of the economy conditional upon some extremely low levels of sovereign credit risk of other economics in the region. Consistent with most other studies, the results show that the impact tends to be stronger in crisis than in boom times.

- $\quad$ Conditional risk estimates are critically important for macroeconomic surveillance for at least two reasons. First, they reveal which economies are systemically important to the global financial system. Secondly, they show which economies and which common risk factors are potentially influential to the risk of the economy concerned. 


\section{INTRODUCTION}

The recent global financial crisis has sent shockwaves to the world economy. The failure of Lehman Brothers in mid-September 2008 triggered widespread funding liquidity stress among financial institutions in the US. Owing to the highly interconnected nature of their business and operational linkages at global level, the resulting strain impinged on the affected institutions transcended across national boundaries at high speed. Within a short period of time, the global interbank funding network was almost paralysed as counterparty risk rocketed. It can be easily observed that, in practically every country, spreads between interbank interest rates and overnight index swaps widened sharply; credit default swap (CDS) spreads soared; and asset markets suffered large sell-offs. Financial crisis of such scale and ferocity was unseen in history. This crisis has definitely shown us the downside of financial globalisation ironically a phenomenon that was often praised as a major driving force behind the spectacular growth and the longevity of the boom phase of economic cycles over the past two decades.

This study is an investigation of the interconnectivity among economies defined by their geographical location or jurisdiction - in the global financial system. ${ }^{2}$ The objective is to try to disentangle their highly complex multilateral interconnected relationships into simple bilateral interdependence linkages during extreme market conditions. Causes underlying the interdependence between the financial systems in any two different geographical regions or jurisdictions - which can be attributed to many factors such as their bilateral trade or investment flows, and other economic or financial ties - will not be explored here. Rather, this paper seeks to analyse the outcomes, i.e. the resulting interconnected relationship between the financial systems of the economies, regardless of what causes it. In our opinion, the uncovering of these bilateral linkages can aid macro-financial surveillance at regional or even global level, as they are critically important in understanding the systemic significance of individual economies in the global financial system.

The remainder of this paper is organised as follows. Section II explains what CoVaR - a quantifiable relationship between the risks of two entities that is fundamental to our investigation - is and how to estimate it. Section III provides the details of the model specification. Data employed in the estimation and empirical results are discussed in Section IV. Section V concludes.

\footnotetext{
2 Wikipedia defines interconnectivity as "a concept that is used in numerous fields such as cybernetics, biology, ecology, network theory, and non-linear dynamics. The concept can be summarised as that all parts of a system interact with and rely on one another simply by the fact that they occupy the same system, and that a system is difficult or sometimes impossible to analyse through its individual parts considered alone" (http://en.wikipedia.org/w/index.php?title=Interconnectivity\&oldid=356799020).
} 


\section{WHAT IS COVAR?}

A common measure of risk is value at risk (VaR), which tries to quantify risk by potential loss. For instance, the VaR of a firm or an investment portfolio refers to the maximum (minimum) amount of losses the firm or investment portfolio may suffer over some periods of normal (abnormal) market conditions at a specific confidence level. In conducting macro-financial surveillance, it is useful to know the risk of the economy in terms of, say, the probability of a sharp fall in its asset prices. The VaR of the economy can provide a reasonable yardstick of such a risk during normal circumstances. However, since VaR focuses on the economy concerned in isolation, the true risk of the economy is often underestimated when other economies come under stress. In view of the high degree of integration of the global economy today, their risks are highly correlated, especially under adverse market conditions. Therefore, it is critically important to devise a risk measure that can take into account the interconnected nature of the global financial system and evaluate how much the risk of the economy may intensify when other economies around it find themselves in troubles.

One way of assessing the degree of intensification of the risk is to estimate the CoVaR of the economy, which can be referred to as the conditional risk of the economy. The CoVaR of the economy is the VaR of the economy conditional upon the $\mathrm{VaR}$ of another economy. Such a bilateral relationship between, say, two emerging market economies, can arise directly from their own economic or financial linkages, or indirectly from their exposures to a set of common risk factors, such as linkage with a third economy, reliance on international capital markets for funding and holding of foreign exchange reserves dominated by a certain currency or financial asset. At a high percentile on the right-hand side of the statistical distribution, this conditional risk basically captures the tail risk, which is the risk associated with extremely poor market circumstances.

The use of CoVaR to explore such conditional risk relationships was pioneered by Adrian and Brunnermeier (2008). ${ }^{3}$ Their study primarily focuses on the contribution of individual financial institutions to systemic risk using accounting and financial ratios and data of the institutions concerned such as equity value and balance sheet information. Chan-Lau (2008) and the International Monetary Fund (2009) adopted a similar approach but used the CDS spreads of financial institutions in the US, Europe and Japan to study their spillover effects. Fong, et al. (2009) estimated CoVaRs to assess the interdependence of financial institutions in Hong Kong but employed data drawn from the stock market, rather than the CDS market.

3 See also Brunnermeier et al. (2009) for discussion of the classification of systemic risk on the system. 
The above studies all use quantile regression, a technique first introduced by Koenker and Bassett (1978) in their empirical work due to its simplicity and robustness in exploring the relationship between variables evaluated at their extremes. ${ }^{4}$ Like in standard least squares regressions, the risk of the economy is expressed as a function of the risk of another economy and their common risk factors in the quantile regression. However, instead of modelling the conditional mean relationships among the variables, the estimated functional relationship is evaluated at a very high quantile, which can be taken as situations in which the economies experience distress or extreme adversity. Compared with standard least squares regressions, the nonlinearity of the functional relationship estimated by means of quantile regression facilitates a more accurate assessment of the co-movements of these risk measures, since their risks are likely to increase together more than proportionately.

Figure 1 offers some intuition on how CoVaR can be interpreted graphically, using the relationship between the changes in the prices of two financial assets $\mathrm{X}$ and $\mathrm{Y}$. The scatter plot shows the quantile regression lines fit at the $1 \%, 50 \%$, and $99 \%$ quantiles. As can be seen, the dispersion of statistical distribution increases with the fall in the price of asset X (as illustrated by comparing the two statistical distributions), suggesting that the relationship between the prices of the two assets at different quantiles is nonlinear. Consider that the price of asset X falls so sharply that it reaches the 99th level of VaR, i.e. a fall of $29 \%$ in this example. Plugging this value in the $99 \%$ quantile regression yields a CoVaR estimate at a fall of $34 \%$ in the price of asset Y. This is much higher than the unconditional estimate of risk, the observed 99th percentile of changes in the price of asset Y, which amounts to only a fall of 20 percentage points.

\section{MODEL SPECIFICATION}

Let's define $\operatorname{VaR}_{q}^{j}$ as the maximum daily change in a certain variable associated with economy $j$ at a confidence level of $(1-q)$. In the model, an economy that experiences a sharp change in the variable, say, a fall in the price of a financial asset at the 99th percentile (i.e. a $1 \%$ probability of such an extreme change during the sample period) is said to be in distress. This (unconditional) change can be statistically represented by

$$
\operatorname{Pr}\left(\Delta X^{j} \leq \operatorname{VaR}_{q}^{j}\right)=q
$$

${ }^{4}$ CoVaR can also be estimated by using extreme value theory. However, the methodology focuses on extreme realisations which ignore the information content of a large portion of the data sample, so the risk measure can be poorly underestimated, especially when the data sample is small. 
where $\Delta X^{j}$ is the change of the variable of economy $j$ and $q$ is the probability of observing such an extreme change.

Let $\operatorname{CoVaR}_{q}^{i l j}$ denote the $\operatorname{VaR}$ of economy $i$ conditional upon economy $j$ at its level of $\operatorname{VaR}_{q}^{j}$. Statistically, it can be specified as:

$$
\operatorname{Pr}\left(\Delta X^{i} \leq \operatorname{CoVaR} R_{q}^{i \mid j} \mid \Delta X^{j}=\operatorname{VaR}_{q}^{j}\right)=q
$$

The specification in equation (2) is essentially the same as that in equation (1). The only difference is that the former also imposes a condition with respect to the risk of economy $j$.

To estimate this conditional risk, a quantile regression is used to relate the variable of economy $i$ with that of economy $j$. Specifically,

$$
\Delta X^{i}=\beta_{0, q}^{i l j}+\beta_{1, q}^{i l j} \Delta X^{j}+\sum_{k=1}^{K} \gamma_{k, q}^{i l j} R_{k}+\varepsilon_{q}^{i l j}
$$

where $R_{k}$ denotes common risk factor $k$ and $\varepsilon$ is the residual. At $q$ quantile, the constant term $\beta_{0}^{i l j}$ represents the characteristics specific to economy $i$ and $\beta_{1}^{\text {ilj }}$ measures how dependent the risk of economy $i$ is on the risk of economy $j$. After estimating the coefficients $\left(\beta \mathrm{s}\right.$ and $\gamma \mathrm{s}$ ) of the quantile regression, $\operatorname{CoVaR}_{q}^{i l j}$ can be obtained by substituting them into the following equation:

$$
\operatorname{CoVaR}_{q}^{i l j}=\hat{\beta}_{0, q}^{i l j}+\hat{\beta}_{1, q}^{i l j} \operatorname{VaR}_{q}^{j}+\sum_{k=1}^{K} \hat{\gamma}_{k, q}^{i j j} R_{k}
$$

The values of the common risk factors are those on the date when $\operatorname{VaR}_{q}^{j}$ is observed. ${ }^{5}$

5 If $\operatorname{VaR}_{q}^{j}$ falls on two dates, the value of the common risk factor is linearly interpolated by the values realised on the two dates using a ratio $r$ calculated from $r V a R_{q, l}^{j}+(1-r) \operatorname{VaR} R_{q, u}^{j}=\operatorname{VaR}_{q}^{j}$ where $\operatorname{VaR}_{q, l}^{j}$ and $V a R_{q, u}^{j}$ are the realised return of economy $j$ just smaller and larger than $\operatorname{VaR}_{q}^{j}$ respectively. 


\section{DATA AND EMPIRICAL RESULTS}

In this section, we analyse the interconnectivity among 11 Asia-Pacific economies in terms of their credit risk linkages. ${ }^{6}$ The credit risks of the economies here are represented by their sovereign CDS spreads, probably the most popular market-based measure of credit risks. In efficient markets, CDS spreads would rapidly adjust to reflect latest global financial conditions or local economic forces that can have an impact on the credit risk of the economy. ${ }^{7}$ Their co-movements should thus convey information on both direct and indirect linkages across economies and on their systemic risks. ${ }^{8}$ In our estimation, daily data of the five-year sovereign CDS spreads of 11 Asia-Pacific economies are employed, covering the period from 15 October 2004 to 25 September 2009 (see Figure 2). ${ }^{9} \quad$ The confidence level is set to be $1 \%$, in other words, the estimated CoVaR measures the maximum increase in the CDS spread that the economies could suffer at the $99 \%$ confidence level.

The set of common risk factors in the quantile regression is used to help control for changes in market or economic conditions other than the shock from economy $j$. It includes: (1) the general risk premium proxied by the difference between the return of MSCI world index and the three-month US treasury bills; (2) the business cycle proxied by the yield spread between the 10-year and three-month US Treasuries; (3) the default risk in the interbank market of the economies proxied by the weighted average spread of the one-year interbank interest rates of the economies over the one-year US Treasury yield; (4) the severity of liquidity squeeze proxied by the yield spread between the three-month general collateral repo rate and the three-month US Treasury rate; (5) the general risk appetite proxied by the weighted average of economies' implied volatility; and (6) the currency fluctuation proxied by the average daily appreciation of the spot rate of all economies against the US dollar.

6 There is potentially a long list of economic and financial variables that can be used for the study. For example, VaR can be represented by the potential fall in equity prices in a certain stock market and the corresponding CoVaR would be the potential fall conditional upon the VaR in another market.

7 Longstaff et. al (2007) finds that sovereign credit risk is driven by global financial market conditions and local economic forces, especially the former.

8 See details in Chan-Lau and Kim (2006).

9 As there are no sovereign CDS spread data available for Singapore and the sovereign CDS spread data for New Zealand only became available from early 2009, we use the CDS data of government-owned firms, Singapore Telecom and Telecom New Zealand, as proxies for the sovereign credit risks of Singapore and New Zealand respectively. With this, the earliest date that the CDS data for the 11 economies were available is 15 October 2004. As the level data are all found to contain a unit root, their first differences are used for estimation. Hence, the VaR here refers to the change in the CDS spread stressed at the 99th percentile. 
Our estimation results are presented in Table $1 .^{10}$ Each cell in Table 1 represents the excess of CoVaR over VaR of the economy listed in the first column at the 99th percentile conditional upon the VaR of another economy listed in the first row at the 99th percentile. For instance, when China comes under stress (as depicted by having its VaR at the 99th percentile), Australia's VaR at the 99th percentile increases by three basis points or $31 \%$ compared with its unconditional VaR. Note that this is not necessarily symmetric. In case Australia is in trouble, China's VaR at the 99th percentile will rise by seven basis points or $47 \%$.

For most of the economies in Asia Pacific, our results show that the conditional risk measured by CoVaR is significantly higher than the unconditional risk measured by VaR (Figure 3). The last column of Table 1 shows that the VaR of the economy at its 99th percentile, on average, rises by nine basis points or $45 \%$ over the unconditional VaR if another economy in the region comes under the same level of stress. Indonesia is found to be most vulnerable in the sense that it suffers the highest conditional risk as evidenced by its largest excess of CoVaR over VaR (27 basis points), followed by the Philippines (19 basis points) and Korea (10 basis points). The two Pacific economies, Australia and New Zealand, register the smallest excess (3 basis points), followed by Japan and Singapore (4 basis points). The last row of the table shows the average increase in the VaRs of other economies at their 99th percentile when the economy is under the same level of stress. Among the 11 economies, China and Korea are found to create potentially the largest impact (13 basis points), and Singapore the smallest ( 6 basis points).

What is the conditional risk made up of? Equation (4) suggests that the CoVaR of an economy is attributable to three potential sources: (i) the economy's own characteristics; (ii) spillover from other economies; or (iii) the associated adverse change in common risk factors. To shed light on how much each of these factors contributes to the conditional risk of the 11 Asia-Pacific economies, we decompose the estimated CoVaRs based on equation (4). Figure 4 summarises the average CoVaRs of the economies by contributing factor. Generally speaking, the economy's own characteristics contribute most to the CoVaRs, accounting for an average of $56 \%$ of the CoVaR or 16 basis points, followed by an average of $24 \%$ or nine basis points attributable to the spillover from other economies. Of the common risk factors, general risk premium contributes an average of $16 \%$ or three basis points, and currency fluctuations an average of $5 \%$ or two basis points.

10 The quasi-likelihood ratio test is used to test the explanatory power of the variables by comparing the unrestricted model (with the constant term and all the variables) with the restricted model (without control variables) in the quantile regression. At the 5\% level of confidence, of all the 110 quantile regression models we estimated, about $89.1 \%$ have a significant difference between the unrestricted and restricted models. 
Are the conditional risks symmetric during good and bad times? Difference between CoVaRs and VaRs suggests that the tail risk cannot be ignored, as the correlation between movements in financial prices - changes in CDS spreads of different economies in this case - often increases sharply under extreme market conditions. A number of empirical studies have recently been devoted to studying whether the strong correlation would occur when market conditions are both extremely good and extremely bad, or only when they are extremely bad. For our study, it would be natural to ask whether the CoVaRs are symmetric or asymmetric under both scenarios. Therefore, we rerun the quantile regression to obtain a set of estimates similar to Table 1 but at the $1 \%$ quantile. These estimates (at 1st percentile) and those presented in Table 1 (at 99th percentile) are plotted against each other cell to cell in Figure $5 .^{11}$ In the scatter plot, points sitting on the 45-degree line suggest equal CoVaRs during boom and crisis times. As $77 \%$ of the points lie below the 45 -degree line, the spillover tends to be stronger in crisis than boom times, a finding that is consistent with most other studies. ${ }^{12}$

\section{CONCLUSION}

Over the past two decades or so, financial markets and banking systems under different jurisdictions have become increasingly integrated. This integration has generated considerable benefits to the global economy, e.g. increases in productivity and macroeconomic risk sharing. However, these benefits do not come without a significant cost. The resulting high degree of interconnectedness and interdependence among individual financial institutions, financial markets and financial systems has exposed them to greater risks of external shocks, increasing their own vulnerabilities as well as the vulnerability of the global financial system as a whole. This is best exemplified by the recent financial crisis: when one of the systems breaks down, the effects can ripple through to other systems via multiple channels - direct and indirect - in no time. This demonstrated interconnectivity among economies in the global financial system shows that few economies can be completely insulated from external influences and that financial turmoil elsewhere can have serious implications for financial stability at home. Hence, policymakers concerned with financial stability can no longer focus on domestic conditions but also developments overseas.

In this paper, we have illustrated a tool that can be used to assess the financial interconnectivity between two economies or, more specifically, how much the risk of one of them may change, depending on the circumstances of the other. When the analysis is applied to a system consisting of more than two economies, the assessment

11 As the CoVaR estimates are all negative at the $1 \%$ quantile, we take the absolute value of them for the ease of presentation.

12 See Bae et al. (2003), Butler and Joaquin (2002), Bekaert, et al. (2003), Dungey et al. (2003) and Bayoumi et al. (2003). 
offers two further insights to policymakers. First, the pair-wise CoVaR estimates reveal which economy or economies (and which risk contributing factors) they must pay more attention to when conducting macroeconomic surveillance. Secondly, the aggregate or average potential impact on the rest of the world highlights which economy or economies are systemically more important than others. ${ }^{13}$

To sum up, the estimation of CoVaRs represents a first step towards analysing the global financial system through the study of the bilateral interdependence linkages between individual economies. It provides a useful tool for policymakers to assess how the risk of an economy may change when its neighbour is under stress. Depending on which neighbour is under stress, the optimal policy response can be significantly different.

13 This latter piece of information is equally critical to effective macroeconomic surveillance, even if the systemically important economies appear to have little direct influence to the economy concerned. 
Figure 1. Scatter plot of declines in the prices of two financial assets

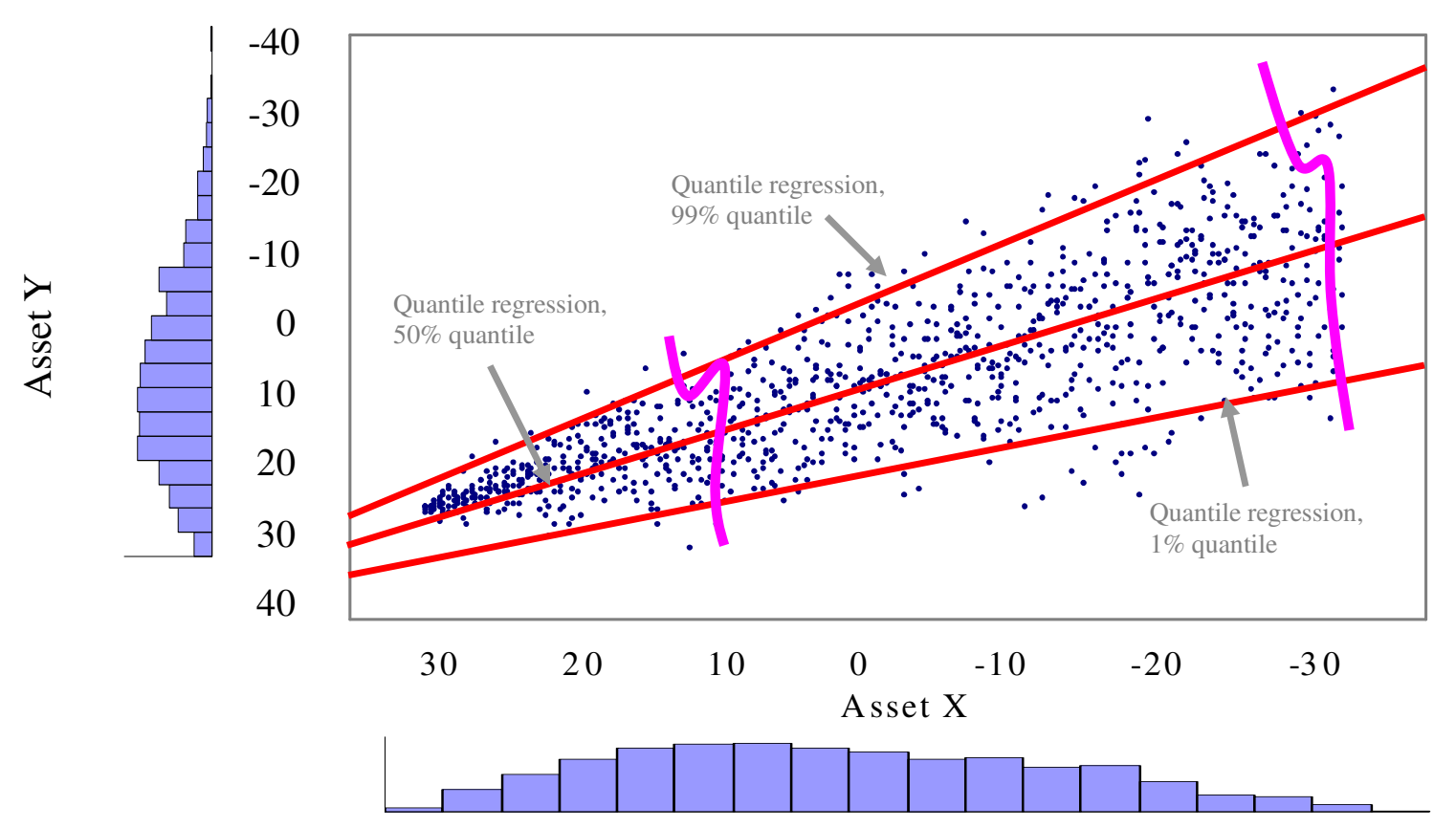

Notes:

(1) For illustrative purposes, the three quantile regression lines and the distributions are roughly sketched out in this graph.

(2) The graph presents roughly a bird's eye view of the distributions. 
Figure 2. Sovereign CDS spread level and their first difference

$\underline{\text { Level of CDS spread }}$

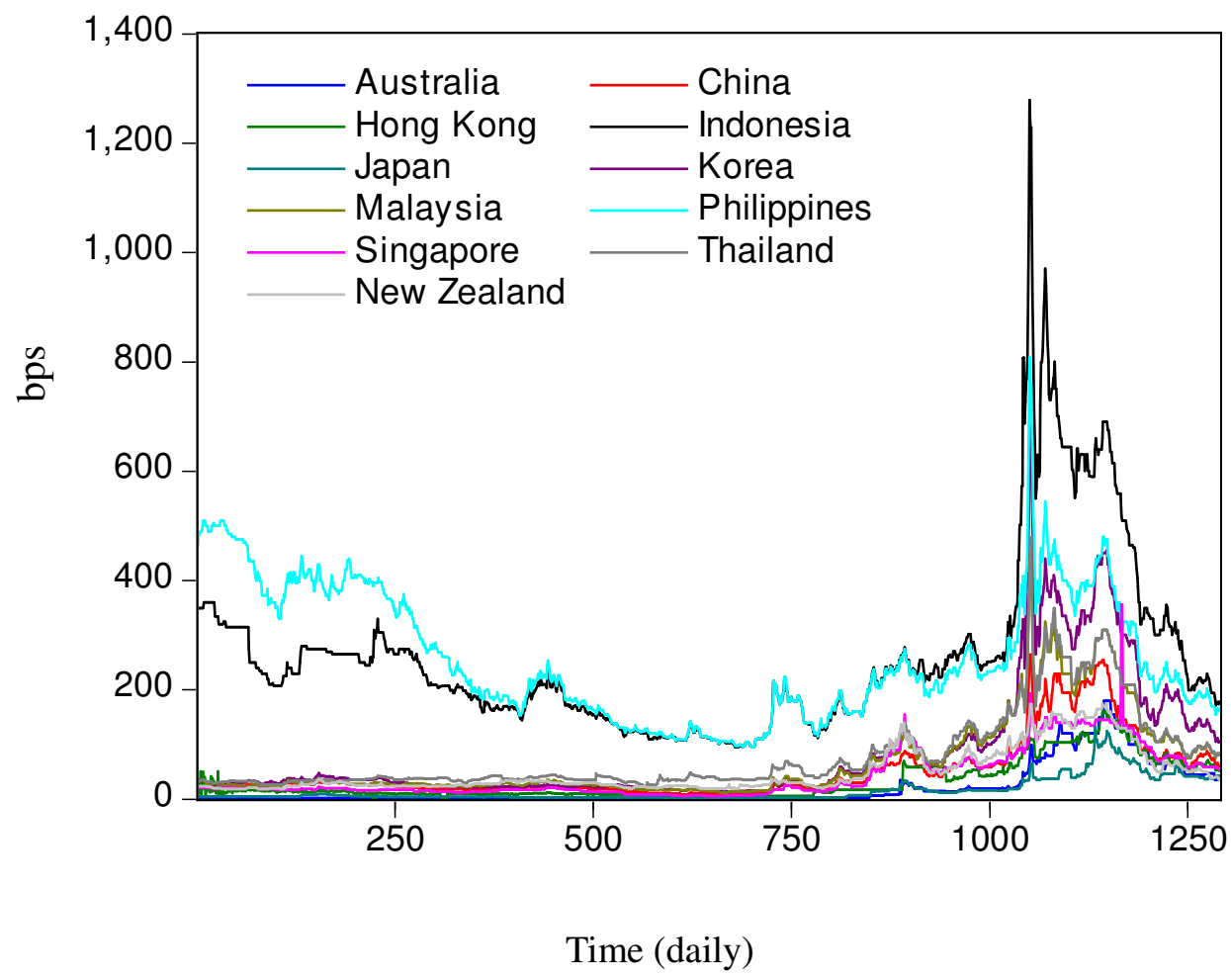

First difference in CDS spread

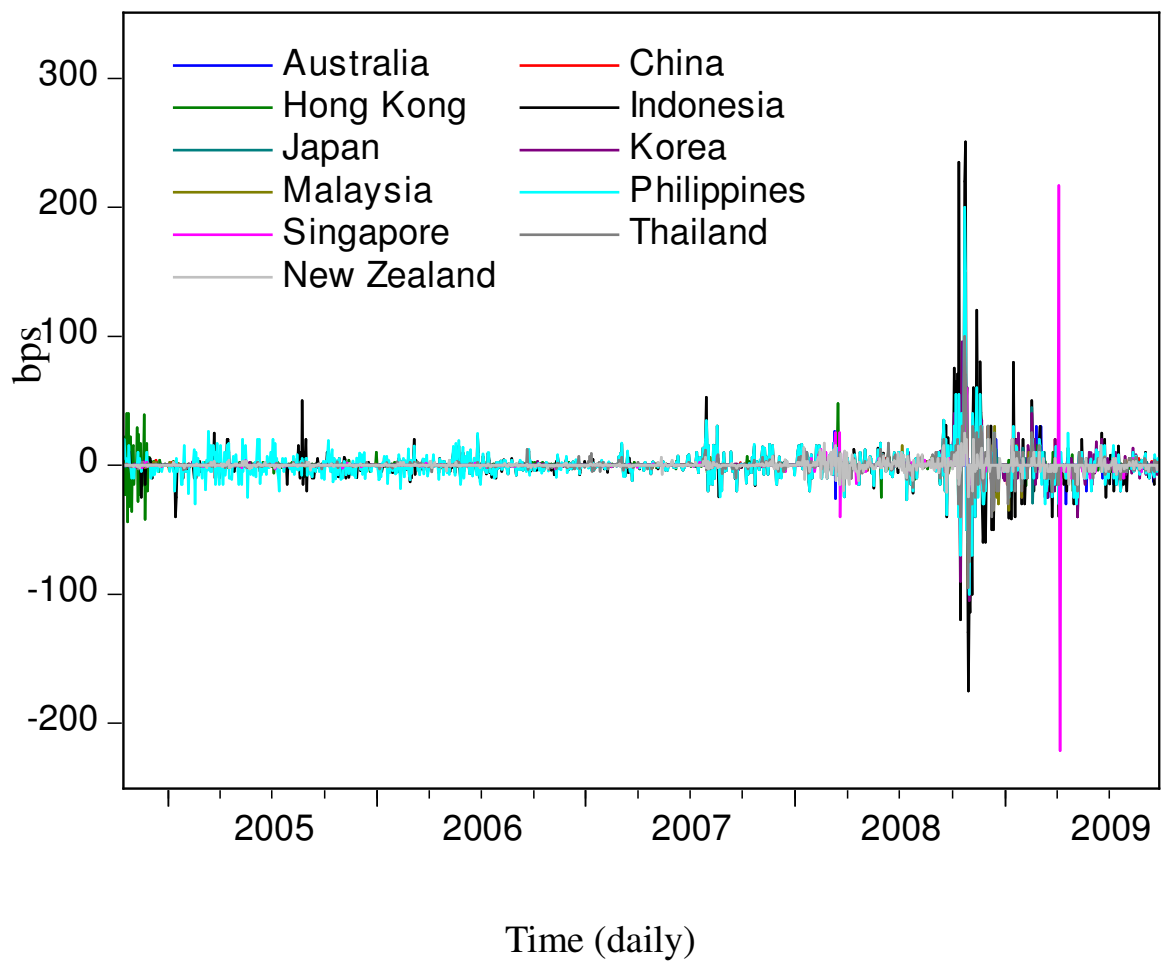


Figure 3. Average CoVaR and VaR of CDS spread change

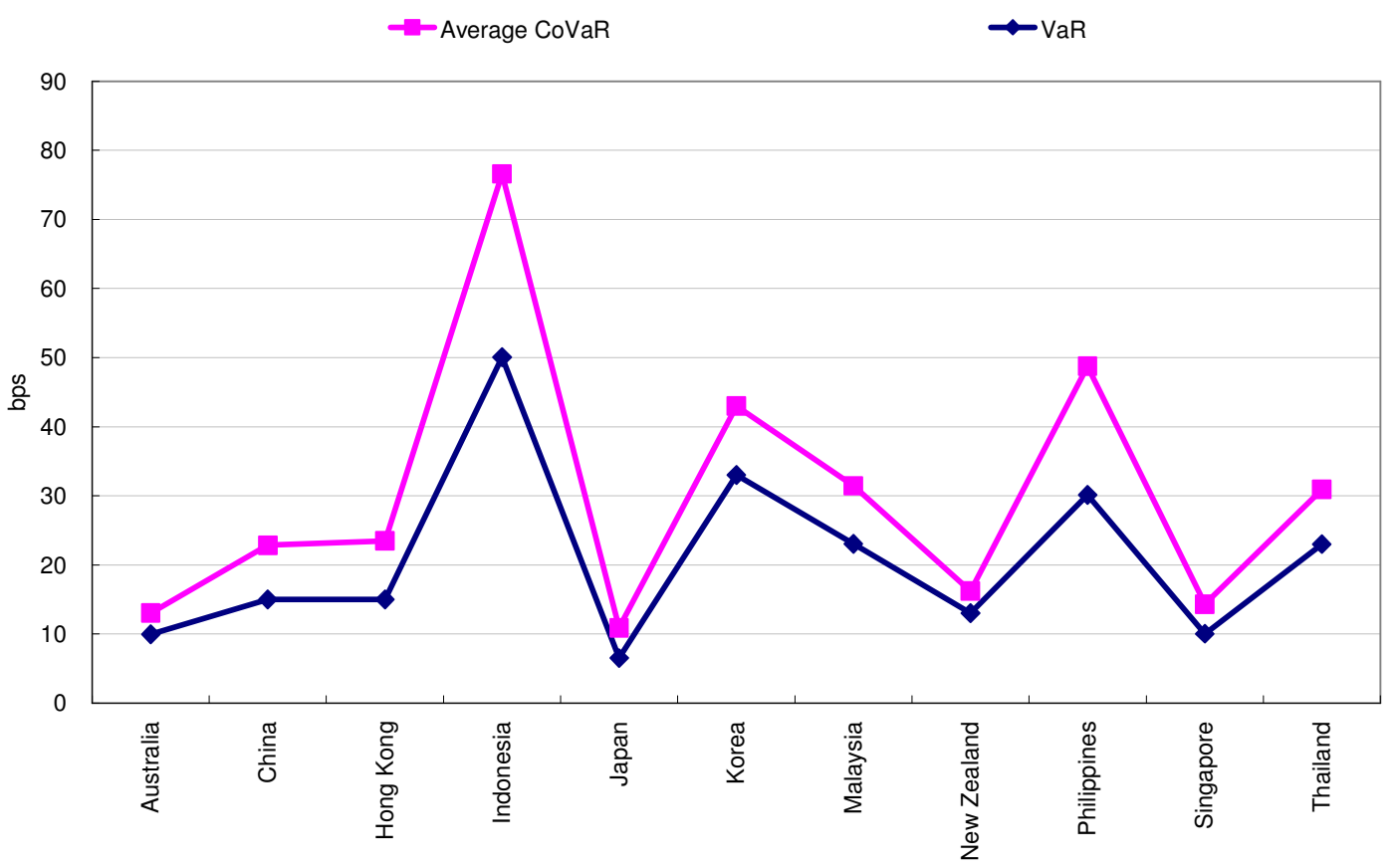

Note: A positive change in CDS spread indicates the sovereign risk of a country increases.

Figure 4. Contribution of risk factors to the CoVaR on average

$\underline{\text { CoVaR (i.e. estimated change in CDS spread) }}$

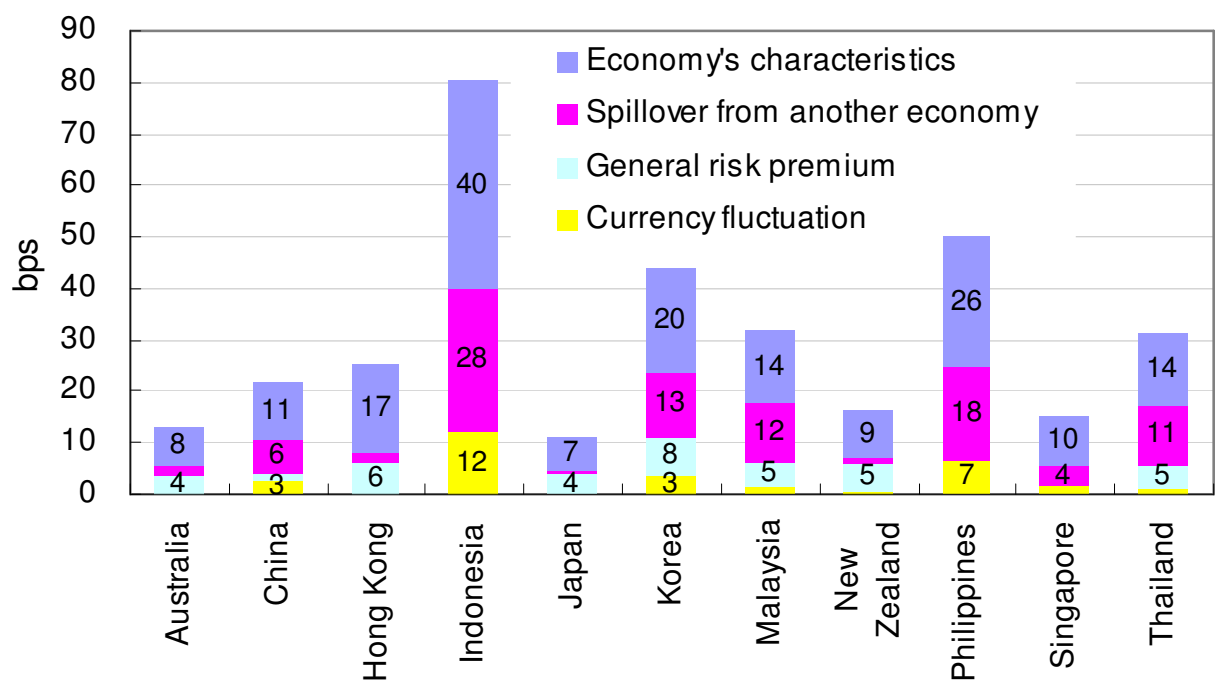

Note: Since the contribution of "other factors" is insignificant, they are not plotted in this figure. 
Figure 5. Spillover in crisis and boom periods (as reflected by CoVaR estimates at 1st and 99th percentiles)

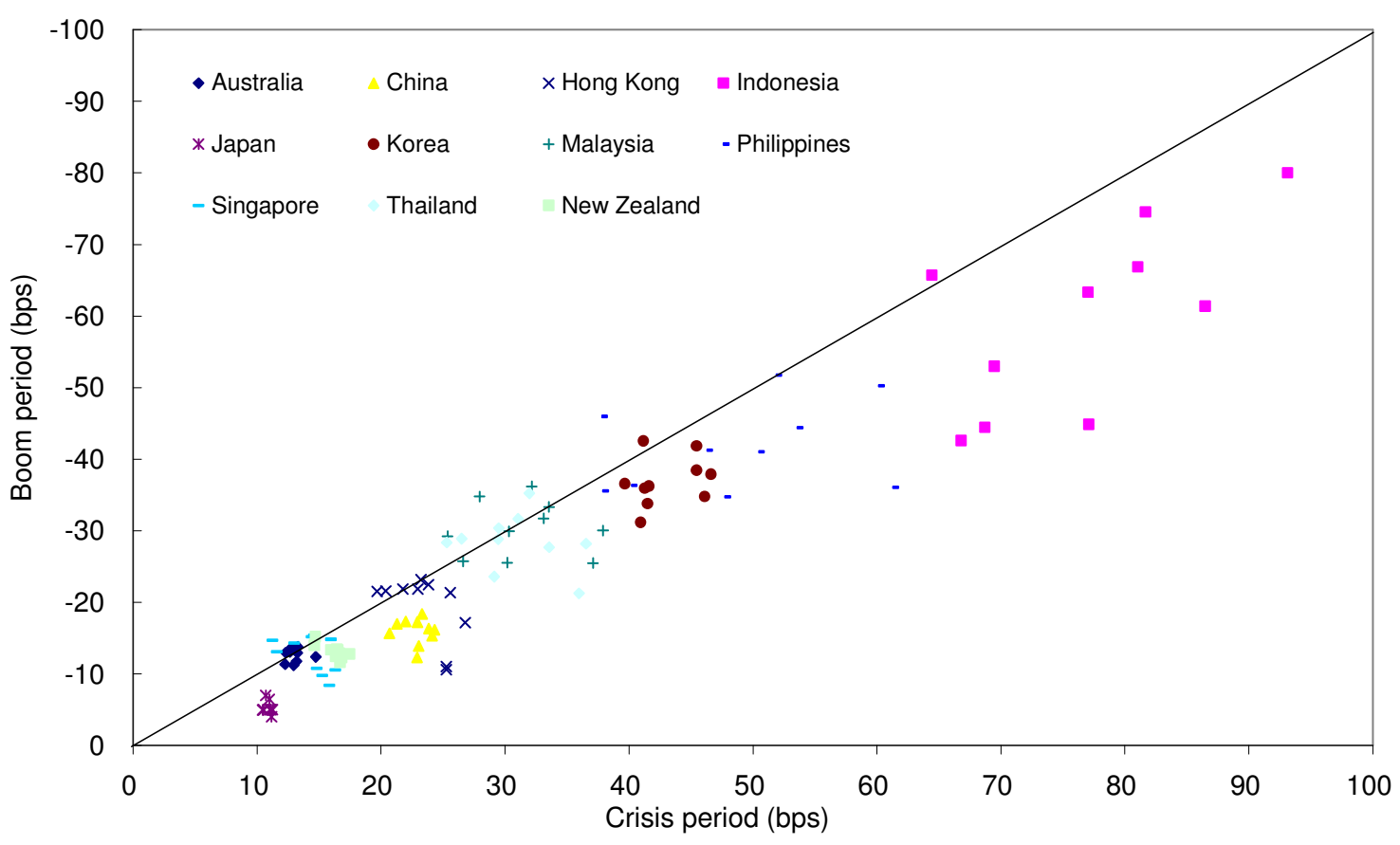


Table 1. The excess of CoVaR over VaR for changes in sovereign CDS spreads, Oct 2004 - Sep 2009 (a)

\begin{tabular}{|c|c|c|c|c|c|c|c|c|c|c|c|c|c|}
\hline & Australia & China & $\begin{array}{l}\text { Hong } \\
\text { Kong }\end{array}$ & Indonesia & Japan & Korea & Malaysia & Philippines & Singapore & Thailand & $\begin{array}{c}\text { New } \\
\text { Zealand }\end{array}$ & VaR & Vulnerability $^{(\mathrm{b})}$ \\
\hline \multicolumn{14}{|c|}{ Absolute increase (in basis points) } \\
\hline Australia & & 3 & 5 & 3 & 3 & 3 & 3 & 2 & 3 & 3 & 2 & 10 & 3 \\
\hline China & 7 & & 8 & 9 & 8 & 9 & 8 & 6 & 6 & 9 & 8 & 15 & 8 \\
\hline Hong Kong & 12 & 8 & & 9 & 10 & 11 & 7 & 8 & 5 & 5 & 10 & 15 & 8 \\
\hline Indonesia & 27 & 43 & 19 & & 17 & 36 & 32 & 27 & 19 & 31 & 14 & 50 & 27 \\
\hline Japan & 4 & 4 & 5 & 4 & & 5 & 5 & 4 & 5 & 5 & 4 & 7 & 4 \\
\hline Korea & 13 & 8 & 14 & 9 & 9 & & 12 & 7 & 8 & 12 & 8 & 33 & 10 \\
\hline Malaysia & 5 & 11 & 7 & 15 & 4 & 14 & & 10 & 2 & 7 & 9 & 23 & 8 \\
\hline Philippines & 18 & 30 & 16 & 20 & 10 & 31 & 22 & & 8 & 23 & 8 & 30 & 19 \\
\hline Singapore & 5 & 6 & 6 & 1 & 6 & 5 & 4 & 2 & & 3 & 5 & 10 & 4 \\
\hline Thailand & 6 & 9 & 6 & 14 & 3 & 13 & 6 & 8 & 2 & & 11 & 23 & 8 \\
\hline New Zealand & 2 & 4 & 2 & 3 & 4 & 4 & 3 & 3 & 3 & 4 & & 13 & 3 \\
\hline Risk Spillover ${ }^{(\mathrm{c})}$ & 10 & 13 & 9 & 9 & 7 & 13 & 10 & 8 & 6 & 10 & 8 & 21 & 9 \\
\hline \multicolumn{14}{|c|}{ Percentage increase $(\%)$} \\
\hline Australia & & 31 & 48 & 33 & 32 & 33 & 27 & 24 & 30 & 28 & 23 & - & 31 \\
\hline China & 47 & & 53 & 59 & 54 & 61 & 53 & 42 & 38 & 62 & 55 & - & 52 \\
\hline Hong Kong & 79 & 55 & & 59 & 69 & 71 & 45 & 53 & 36 & 31 & 69 & - & 57 \\
\hline Indonesia & 54 & 86 & 39 & & 34 & 73 & 63 & 54 & 37 & 62 & 29 & - & 53 \\
\hline Japan & 69 & 60 & 72 & 62 & & 70 & 72 & 61 & 70 & 71 & 65 & - & 67 \\
\hline Korea & 40 & 25 & 41 & 26 & 26 & & 38 & 20 & 24 & 38 & 25 & - & 30 \\
\hline Malaysia & 21 & 46 & 32 & 65 & 16 & 61 & & 44 & 10 & 31 & 40 & - & 36 \\
\hline Philippines & 59 & 100 & 54 & 68 & 34 & 104 & 72 & & 26 & 78 & 26 & - & 62 \\
\hline Singapore & 52 & 59 & 62 & 12 & 58 & 48 & 43 & 15 & & 30 & 45 & - & 42 \\
\hline Thailand & 27 & 39 & 28 & 59 & 15 & 56 & 28 & 35 & 10 & & 46 & - & 34 \\
\hline New Zealand & 12 & 34 & 13 & 25 & 28 & 29 & 26 & 22 & 27 & 28 & & - & 25 \\
\hline Risk Spillover ${ }^{(\mathrm{c})}$ & 46 & 53 & 44 & 47 & 36 & 61 & 47 & 37 & 31 & 46 & 42 & - & 45 \\
\hline
\end{tabular}

Notes: (a) Each cell reports the estimated increase in the VaR (measured by changes in sovereign CDS spread) of the corresponding economy listed under the first column at the 99th percentile conditional upon the VaR of the corresponding economy listed in the row at the 99th percentile.

(b) Vulnerability is the row average of the conditional risks facing the economy.

(c) Risk spillover refers to the column average of the conditional risks suffered by other economies when the economy listed in the column is under stress. 


\section{REFERENCES}

Adrian, T. and Brunnermeier, M.K. (2008): "CoVaR", Federal Reserve Bank of New York Staff Report, No.348, September.

Bae, K., Karolyi, G., and Stulz, R. (2003) "A New Approach to Measuring Financial Contagion”, Review of Financial Studies, 16, 717-763.

Bayoumi, T., Fazio, G., Kumar, M. and MacDonald, R. (2003): "Fatal attraction: A new measure of contagion", IMF Working paper, WP/03/80.

Bekaert, G., Harvey, C.R., and Ng A. (2003): "Market integration and contagion”, Journal of Business, Vol. 78(1), 39-70.

Brunnermeier, M., Crockett, A., Goodhart, C., Persaud, A.D., and Shin, H. (2009): "The Fundamental Principles of Financial Regulation", Geneva Reports on the World Economy 11, Preliminary Conference Draft. Available at www.voxeu.org/reports/Geneva11.pdf.

Butler, K.C. and Joaquin, D.C. (2002), "Are the Gains from International Portfolio Diversification Exaggerated? The Influence of Downside Risk in Bear Markets?" Journal of International Money and Finance, Vol. 21, pp. 981-1011.

Chan-Lau, J.A. (2008): "Default Risk Codependence in the Global Financial System: Was the Bear Stearns Bailout Justified?". Available at http://www.bcentral.cl/conferencias-seminarios/seminarios/pdf/Chan-Lau.pdf

Chan-Lau, J.A. and Kim, Y.S. (2005) "Equity prices, credit default swaps, and bond spreads in emerging markets", ICFAI Journal of Derivatives Markets, 2, 7-23.

Dungey, M., Fry, R., Gonzalez-Hermosillo, B. and Martin, V. (2003): "Unanticipated Shocks and Systemic Influences: The Impact of Contagion in Global Equity Markets in 1998", IMF Working paper, WP/03/84.

Fong, T.P.W., Fung, L.K.P., Lam, L.L.F., and Yu, IW (2009) "Measuring the interdependence of banks in Hong Kong", Hong Kong Monetary Authority Working Paper 19/2009.

International Monetary Fund (2009): "Assessing the Systemic Implications of Financial Linkages", Global Financial Stability Report, Chapter 2, April.

Koenker, R. and Bassett, G. (1978): "Rregression Quantiles", Econometrica, 46(1), 33-50.

Longstaff, F.A., Pedersen, L.H., and Singleton, K.J. (2007): "How sovereign is sovereign credit risk", NBER Working Paper 13658. 